\title{
Paracentric Inversions Found in Prenatal Diagnosis
}

\author{
Shin Yeong Lee', Bom Yi Lee ${ }^{1}$, Ju Yeon Park', Eun Young Choi ${ }^{1}$, Yeon Woo Lee ${ }^{1}$, Ah Rum Oh', Hyun Mee Ryu ${ }^{1,2}$ and So Yeon Park* \\ ${ }^{1}$ Laboratoy of Medical Genetics, Cheil General Hospital and Women's Healthcare Center, Seoul, Korea \\ ${ }^{2}$ Department of Obstetrics and Gynecology, Cheil General Hospital and Women's Healthcare Center, Kwandong University, College of Medicine, \\ Seoul, Korea
}

\begin{abstract}
Purpose: This study was designed to confirm whether the paracentric inversions of fetuses and parents may be harmless. Materials and methods: We report 10 cases $(0.14 \%)$ with paracentric inversions among 7,181 prenatal cases observed during prenatal diagnosis performed at Cheil General Hospital between January 2009 and June 2013. We used cytogenetic GTLand RBG-banding techniques.

Results: Of the 10 cases, nine cases were transmitted from each of the parents, and one case was de novo. Nine cases were phenotypically normal up to one month of age after birth. One case was lost to follow-up. We present prenatal diagnosis and follow-up examination of the fetuses with paracentric inversion.

Conclusion: Based on our cases, most paracentric inversions are considered to be harmless. The precise identification of paracentric inversions might be clinically important and helpful for genetic counseling.
\end{abstract}

Key words: Paracentric inversion, Prenatal diagnosis, Amniocentesis, Chorionic villus sampling

\section{Introduction}

Inversions are intrachromosomal structural rearrangements arising from two breaks and reinsertion of the chromosomal segment after a rotation of $180^{\circ}$. While pericentric inversions include the centromere in the inverted segment, paracentric inversions are a chromosome rearrangement that two breaks and reinsertion occur within the same chromosome arm, so the inverted segment does not include the centromere. ${ }^{1,2)}$

Although the incidence of paracentric inversions has not been completely established, the overall incidence ranges from $0.1-0.5 \%$. ${ }^{3)}$ Some studies have indicated a 10-fold lower incidence of paracentric inversions than pericentric inversions. ${ }^{4)}$ Approximately $50.0 \%$ of paracentric inversions were found during prenatal diagnosis by chance. ${ }^{2)}$
Inversions are balanced rearrangements of chromosomes, and the vast majority of paracentric inversions seem to be harmless. ${ }^{5}$ The risk of having a phenotypically abnormal child for carriers of paracentric inversions due to the production of unbalanced gametes resulting from recombination during meiotic crossover has been thought to be low. ${ }^{6}$ However, a few cases of abnormal offspring due to classic recombination of inversion have been described. Spontaneous abortion, infertility, and mental retardation and/or congenital malformation of offspring have also been reported among paracentric inversion carriers. ${ }^{2)}$

In this study, we characterized paracentric inversions identified in 10 cases observed in prenatal diagnosis at our center during a five-year period.

Received: 25 November 2013, Revised: 16 December 2013, Accepted: 24 December 2013, Published: 31 December 2013

*Corresponding author: So Yeon Park, Ph.D.

Laboratory of Medical Genetics, Cheil General Hospital and Women's Healthcare Center, Kwandong University College of Medicine, 1-19 Mukjeongdong, Jung-gu, Seoul 100-380, Korea

Tel: +82-2-2000-7682, Fax: +82-2-2278-4574, E-mail: paranip5@hanmail.net

Conflict of interest: We declare that we do not have any conflicts of interests.

(c) This is an open-access article distributed under the terms of the Creative Commons Attribution Non-Commercial License (http://creativecommons.org/licenses/by-nc/3.0/) which permits unrestricted non-commercial use, distribution, and reproduction in any medium, provided the original work is properly cited.

(c) Copyright 2013 by the Korean Society of Medical Genetics 


\section{Materials and Methods}

\section{Subjects}

This study was approved by the institutional ethics committee of Cheil General Hospital and included 10 cases with paracentric inversion chromosomes that were referred to our clinic for prenatal diagnosis between January 2009 and June 2013. Fetal karyotyping was performed via amniocentesis and chorionic villus sampling (CVS). Indications for invasive prenatal diagnosis included abnormal ultrasound finding, maternal serum screening positive for Down syndrome, parental chromosomal aberrations, fetal chromosomal aberration, and advanced maternal age.

\section{Cytogenetic analysis}

Metaphase chromosome preparations from amniotic fluid, chorionic villus, and peripheral blood lymphocytes were performed according to cytogenetic standard procedures and stained using GTL-and RBG-banding techniques.) The karyotype description followed the International System for Human Cytogenetic Nomenclature 2013. ${ }^{8}$ At least 25-50 metaphases were analyzed for each case. Parental chromosome analysis from peripheral blood cells at high-resolution (700-850 band levels) was performed to confirm parental inheritance.

\section{Results}

We found 10 prenatal paracentric inversion cases among 7,181 prenatal cases from January 2009 to June 2013. The incidence of prenatal paracentric inversions was $0.14 \%$ in the present prenatal diagnosis cases. Table 1 summarizes 10 cases with paracentric inversion observed in prenatal diagnosis. The 10 cases of paracentric inversion involved chromosomes 1 , $2,3,4,7,18$, and $X$ (Fig. 1). Paracentric inversion in eight cases were found during prenatal cytogenetic diagnosis performed because of abnormal ultrasound finding $(\mathrm{N}=1)$, maternal serum screening positive for Down syndrome ( $\mathrm{N}=3$ ), fetal chromosomal aberration $(\mathrm{N}=1)$, and advanced maternal age $(\mathrm{N}=3)$. Two cases referred to prenatal diagnosis for parental chromosomal aberrations. Fetal karyotyping was performed via amniocentesis in eight cases and CVS in two cases. Of the 10 cases, six cases were inherited from maternal, three cases were inherited from paternal, and one case was a de novo inversion. Nine cases were resulted in a phenotypically normal baby at birth, one case was lost to follow-up.

Fetal chromosomal aberration of case 4 was revealed inv(3) by amniocentesis in the first pregnancy, which was inherited from mother. In the third pregnancy, she delivered phenotypically normal twin girls with the same rearrangement, inv(3). In the

Table 1. Cases with Paracentric Inversion Observed in Prenatal Diagnosis

\begin{tabular}{|c|c|c|c|c|c|c|c|c|c|c|}
\hline \multirow[b]{2}{*}{ Case } & \multirow[b]{2}{*}{ Fetal Karyotype } & \multicolumn{4}{|c|}{ Obstetric history } & \multirow[b]{2}{*}{ Indication } & \multirow[b]{2}{*}{ Specimen } & \multirow[b]{2}{*}{ Origin } & \multirow[b]{2}{*}{ Parental Karyotype } & \multirow[b]{2}{*}{ Follow-up } \\
\hline & & $\begin{array}{l}\text { Maternal } \\
\text { age }\end{array}$ & G & $P$ & SA & & & & & \\
\hline 1 & $46, X Y, \operatorname{inv}(1)(q 42 q 44)$ & 31 & 1 & & & $\begin{array}{l}\text { Fetal hydrops, } \\
\text { cystic hygroma }\end{array}$ & CVS & mat & $46, X X, \operatorname{inv}(1)(q 42.13 q 44)$ & Follow-up loss \\
\hline 2 & 46,XX,inv(2)(p13p16) & 33 & 1 & & & High risk for Down & $A F$ & dn & Nomal & $\begin{array}{l}\text { Phenotypically normal } \\
\text { at } 10 \text { months after birth }\end{array}$ \\
\hline 3 & 46,XY,inv(3)(q13.2q22) & 35 & 2 & 1 & & AMA & $\mathrm{AF}$ & pat & 46,XY,inv(3)(q13.2q22.1) & $\begin{array}{l}\text { Phenotypically normal } \\
\text { at seven months after birtt }\end{array}$ \\
\hline 4 & $46, X Y, \operatorname{inv}(3)(q 13.2 q 21)$ & 34 & 4 & 1 & 2 & $\begin{array}{l}\text { Maternal chromosomal } \\
\text { aberration }\end{array}$ & CVS & mat & 46,XX,inv(3)(q13.2q21.3) & $\begin{array}{l}\text { Phenotypically normal } \\
\text { at } 15 \text { months after birth }\end{array}$ \\
\hline 5 & $46, X Y, \operatorname{inv}(4)(q 31.3 q 34)$ & 35 & 2 & & 1 & $\begin{array}{l}\text { Paternal chromosomal } \\
\text { aberration }\end{array}$ & AF & pat & 46,XY,inv(4)(q31.3q34.2) & $\begin{array}{l}\text { Phenotypically normal } \\
\text { at two years old }\end{array}$ \\
\hline 6 & 46,XY,inv(4)(p14p16.1) & 35 & 1 & & & High risk for Down & AF & pat & 46,XY,inv(4)(p14p16.1) & $\begin{array}{l}\text { Phenotypically normal } \\
\text { at three years old }\end{array}$ \\
\hline 7 & $46, X X, \operatorname{inv}(7)(q 21.3 q 36)$ & 32 & 5 & 1 & 1 & High risk for Down & $A F$ & mat & $46, X X, \operatorname{inv}(7)(q 21.3 q 36.3)$ & $\begin{array}{l}\text { Phenotypically normal } \\
\text { at six months after birth }\end{array}$ \\
\hline 8 & 46,XY,inv(7)(q21.1q34) & 41 & 4 & 2 & & AMA & $A F$ & mat & $46, X X, \operatorname{inv}(7)(q 21.1 q 34)$ & $\begin{array}{l}\text { Phenotypically normal } \\
\text { at three weeks after birth }\end{array}$ \\
\hline 9 & $46, X X, \operatorname{inv}(18)(q 21.1 q 22)$ & 38 & 3 & 1 & 1 & $\begin{array}{l}\text { Fetal chromosomal } \\
\text { aberration }\end{array}$ & AF & mat & 46,XX,inv(18)(q21.1q22.1) & $\begin{array}{l}\text { Phenotypically normal } \\
\text { at four month after birth }\end{array}$ \\
\hline 10 & $46, Y, \operatorname{inv}(X)(q 21.2 q 24)$ & 39 & 2 & 1 & & AMA,INT(3.1mm) & AF & mat & 46,X,inv $(X)(q 21.1 q 23)$ & $\begin{array}{l}\text { Phenotypically normal } \\
\text { at } 21 \text { months after birth }\end{array}$ \\
\hline
\end{tabular}

AF, amniotic fluid; CVS, chorionic villus sampling; G, gravidity; P, parity; SA, spontaneous abortion; AMA, advanced maternal age; INT, increased nuchal translucency; High risk for Down: maternal serum screening positive for Down syndrome; pat, paternal; mat, maternal; dn, de novo; Phenotypically normal. 
present pregnancy, CVS was performed at 11 weeks of gestation for prenatal diagnosis at our center. The result of the fetal karyotype was the inversion as maternal karyotype.

In case 5 , the previous fetal chromosomal aberration including inversion chromosome 4 and deletion chromosome 7 was found by amniocentesis. Parental chromosomal analysis was performed and paternal karyotype had an inversion chromosome 4 . In the present pregnancy, amniocentesis was performed at 15 weeks of gestation due to paternal chromosomal aberration. Fetal karyotype was revealed inv(4) same as paternal karyotype.

Prenatal cytogenetic analysis of case 9 was referred for
A

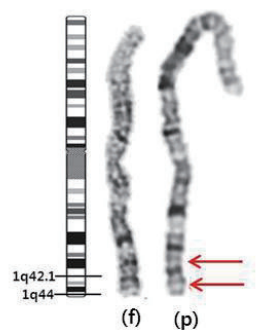

C

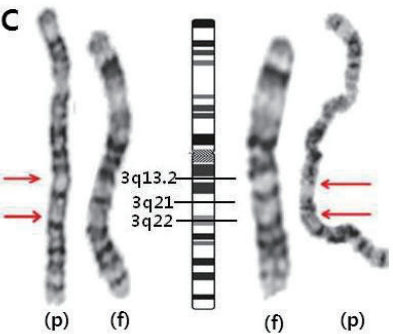

E

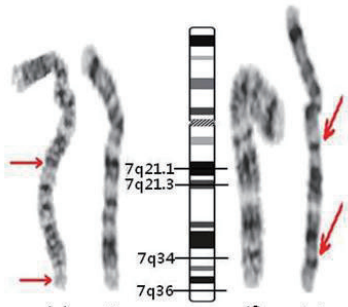

(p) (f)
B

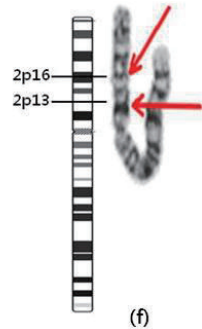

D

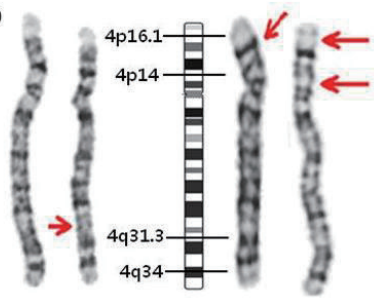

(p) (f)
$\mathbf{F}$

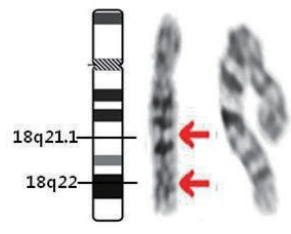

(f)

G

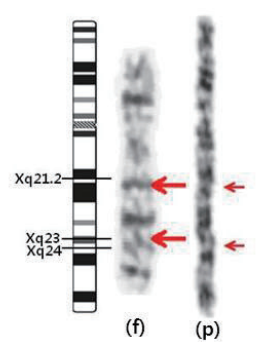

Fig. 1. Partial chromosome ideograms and GTL-banded karyotypes of 10 cases of paracentric inversion. Parental karyotypes $(p)$ and fetal karyotypes (f). (A) inv(1)(q42q44)(case 1) (B) inv(2)(p13p16)(case 2) (C) inv(3)(q13.2q22)(case 3,left) and inv(3)(q13.2q21)(case 4,right) (D) inv(4)(q31.3q34)(case 5,left) and inv(4)(p14p16.1)(case6, right) (E) inv(7)(q21.3q36)(case7,left) and inv(7)(q21.1q34)(case8,right) (F) inv(18)(q21.1q22)(case 9) (G) inv(X)(q21.2q24)(case 10).

amniocentesis because of fetal chromosomal aberration, add(18) (q21.1) diagnosed at a local hospital. Familial cytogenetic analysis was performed for the parents and maternal grandparents. The same rearrangements with inv(18) were found in the karyotype of mother and maternal grandmother.

\section{Discussion}

We found the 10 prenatal paracentric inversion cases between January 2009 and June 2013 in prenatal diagnosis. The incidence of prenatal paracentric inversions was $0.14 \%$ in our prenatal diagnosis cases. This result is in accordance with a previously published report with an overall incidence of paracentric inversion of $0.1-0.5 \% .{ }^{3)}$ Paracentric inversions have been identified in all chromosomes. The chromosomes most commonly reported to have paracentric inversions ( $>5 \%$ of the total) are chromosomes $1,3,5,6,7,11$, and 14. Less frequently identified chromosomes are chromosomes 4, 16, 17, 18, 19, 20, 21, 22, and $Y^{2,5,6)}$ Our 10 cases involved chromosomes 1, 2, 3, 4, 7, 18, and $X$. The nine cases were observed in A-C group chromosomes, except for case 9 . Of our 10 cases, familial inversions were transmitted more frequently by the mother in six cases, as compared to the father in three cases, and only one case was a de novo inversion. Cystic hygroma of case 1 may or may not be causally related to the presence of a paracentric inversion of chromosome 1. An inv(1)(q42q44) case reported by Speevak et al. ${ }^{9}$, which turned out to be an intra-chromosomal insertion in the mother, ins(1)(q44q42q43), was not associated with cystic hygroma. We found no evidence that the finding of cystic hygroma was directly relevant to paracentric inversion.

Case 2 was identified as a de novo paracentric inversion rearrangement. Parental karyotypes were both normal. According to the reports, which was previously announced, de novo paracentric inversion were more commonly associated with spontaneous abortion, mental retardation and/or multiple congenital abnomalities, or genetic syndromes than inherited paracentric inversions. ${ }^{2)}$

Abnormalities seen in patients with apparently balanced inversions could be due to one of the two: a part of a chromosome that appears balanced is in reality missing or added, or no material is missing but a breakpoint has occurred in the gene rendering it nonfunctional. The presence of sub-microscopic deletions and duplications can be confirmed through the combined banding techniques, FISH and array $\mathrm{CGH}^{10)}$ Unfortunately, our case was not performed an additional testing as array $\mathrm{CGH}$. It is apply the overall risk for two-break rearrangements as 6.7 
$\%$ to counseling parents when a de novo inversion is detected in prenatal diagnosis. ${ }^{111}$

Some reports mentioned that paracentric inversion breakpoints seemed to correlate with a known gene/syndrome location. ${ }^{2)}$ We considered that the inversions seen in cases 7 and 8 might be associated with ectrodactyly-ectodermal dysplasia-cleft (EEC) syndrome (also known as "split hand/split foot malformation (SHSF) syndrome"). SHSF syndrome was associated with a paraentric inversion of chromosome $7 q 21-q 22 .{ }^{12)}$ Akita et al. ${ }^{13)}$ reported that EEC syndrome was associated with inv(7) (q22.1q36.3) in a little girl and her father. She had bilateral cleft lip and palate, limited extension of the elbow joints, bilateral ectrodactyly of the hands and feet, and various other abnormalities. Her father exhibited a normal phenotype. ${ }^{13)}$ In the present study, breakpoint of case 7 and 8 was 7q21.3 and $7 q 21.1$, respectively. There are overlapped the mutation locus of SHSF syndrome. However, the neonate in case 7 and 8 had normal phenotype at birth. Case 9, inv(18)(q21q22) is likely associated with 18q-syndrome. 18q-syndrome's critical region is estimated to be at 18q21.3 or 18q22.3. . $^{14,15)}$ Keppler-Noreuil et al. ${ }^{16)}$ reported a case of inv(18)(q21.1q23) of a mother and her daughter involving mental retardation and hearing loss. The breakpoints of our case were 18q21.1 and q22 and the mother, maternal grandmother, and the newborn, all of whom were phenotypically normal. ${ }^{17)}$

In the family in case 10, paracentric inv $(X)$ is associated with normality. A normal phenotype with no defects would be anticipated in future heterozygotes or hemizygotes. ${ }^{18)}$ Breakpoints in the critical region at Xq13-q21 and at Xq26-q27 might compromise ovarian integrity. ${ }^{19,20)}$ One article reported that a woman with de novo inv $(X)(q 13 q 24)$ had ovarian dysgenesis such as primary amenorrhea and absence of pubertal development. ${ }^{21)}$

Most paracentric inversions are considered to be harmless. However, meiotic crossover in the inverted segment may generate chromosomally unbalanced gametes. Most of the zygotes resulting from the chromosomally unbalanced gametes would be lost very early, even before implantation. ${ }^{2)}$ The risk of production of unbalanced gametes by a carrier is thought to be small, and some reviews have confirmed that the risk of abnormal recombinants is very low. Therefore, carriers of paracentric inversions are low risk for having an abnormal liveborn child. ${ }^{6)}$

All the cases were natural pregnancy and three cases was the first pregnancy. Case 4, 5, 7, 9 experienced the spontaneous abortion. Each spontaneous aborted case was not performed cytogenetic follow-up testing. However, there was no evidence of a direct correlation between the paracentric inversion and the abortions. Also, there was no case was observed an abnormal liveborn child with paracentric inversion.

Pettenati et al. ${ }^{2)}$ stated in a review of 446 paracentric inversions cases that the risk of viable recombinants is 3.8\%. They suggested at least 20\% risk for mental retardation and/or multiple congenital abnormalities in cases of paracentric inversion identified at amniocentesis, whether inherited or de novo. ${ }^{2)}$ However, there are some reports that the opinion of Pettenati et al. ${ }^{2)}$ remains controversial. ${ }^{22,23)}$ Even though the risk of paracentric inversion-mediated abnormal recombinants is low, we should keep in mind that paracentric inversions can be related to infertility, recurrent spontaneous abortion or fetal abnormalities, which can include cases of mental retardation or microcephaly. ${ }^{2)}$

In addition, sub-microscopic deletions and duplications in low-resolution karyotype analysis can be missed. Unless whole chromosome morphology is altered and crucial landmark bands are shifted, the rearrangement may be undetected." Because of the high risk of recombinants for carriers of insertions, every effort should be made to distinguish inversions from insertions. Madan and Menko ${ }^{24)}$ described the general risk for a recombinant child as approximately 15\%, and for particular insertions it may be much higher. It is also important to determine whether insertions or inversions in fetus with apparently the same parental inversion are actually recombinants with a small deletion or a duplication. ${ }^{25)}$ Also paracentric inversions undetected or misinterpreted as other chromosomal rearrangements in some cases because any changes in the banding pattern in some chromosomes may be difficult to recognize and because of the similarity of the banding pattern in the inverted segment. ${ }^{6}$ In case 9, the fetal karyotype interpreted at first as an unbalanced type with addition at long arm of chromosome 18. A high-resolution chromosomal analysis and available molecular genetic techniques should be utilized to identify possible imbalances between apparently similar parental and fetal inversions. ${ }^{1)}$

In conclusion, we have to give attention in interpreting the results of prenatal chromosome analysis to an accurate detection for all paracentric inversions.

\section{References}

1. Inversions. In: Gardner RJM, Sutherland GR, Shaffer LG. editors, Chromosome abnormalities and Genetic counseling, 4th ed, New York: 
Oxford University Press 2012:161-82.

2. Pettenati MJ, Rao PN, Phelan MC, Grass F, Rao KW, Cosper P, et al. Paracentric inversions in humans: a review of 446 paracentric inversions with presentation of 120 new cases. Am J Med Genet 1995;55:171-87.

3. Bhatt S, Moradkhani K, Mrasek K, Puechberty J, Lefort G, Lespinasse $J$, et al. Breakpoint characterization: a new approach for segregation analysis of paracentric inversion in human sperm. Mol Hum Reprod 2007;13:751-6.

4. Groupe de CytogénéticiensFrançais. Paracentric inversions in man. A French collaborative study. Ann Genet (Paris) 1986;29:169-76.

5. Madan K, Seabright M, Lindenbaum RH, Bobrow M. Paracentric inversions in man. J Med Genet 1984;21:407-12.

6. Madan K. Paracentric inversions: a review. Hum Genet 1995;96:503-15.

7. Kim JW, Park SY, Ryu HM, Lee DE, Lee BY, Kim SY, et al. Molecular and clinical characteristics of 26 cases with structural Y chromosome aberrations. Cytogenet Genome Res 2012;136:270-7.

8. Structural chromosome rearrangements. In: Shaffer LG, Schmid M, McGowan-Jordan J. Editors, An International System for Human Cytogenetic Nomenclature (2013), Basel:S Karger 2013:59-84.

9. Speevak M, Hunter AG, Hughes $H_{1}$ Cox DM. A familial paracentric inv(1) (q42q44) resulting in a child with a del(1)(q42) karyotype. Ann Genet 1985;28:177-80.

10. Hales HA, Peterson CM, Carey J, Hecht BK, Hecht F. Prenatal detection of de novo paracentric inversion 46,XX,inv(14)(q22q32.1) in a normal child: report and review of the literature. Am J Med Genet 1993;47:848-51.

11. Warburton $D$, Twersky S. Risk of phenotypic abnormalities in paracentric inversion carriers. Am J Med Genet 1997;69:219.

12. Palmer SE, Scherer SW, Kukolich M, Wijsman EM, Tsui LC, Stephens K, et al. Evidence for locus heterogeneity in human autosomal dominant split hand/split foot malformation. Am J Hum Genet 1994;55:21-6.

13. Akita S, Kuratomi H, Abe K, Harada N, Mukae N, Niikawa N. EC syndrome in a girl with paracentric inversion (7)(q22.1;q36.3). Clin Dysmorphol 1993;2:62-7.
14. Wilson MG, Towner JW, Forsman I, Siris E. Syndromes associated with deletion of the long arm of chromosome 18[del(18q)]. Am J Med Genet 1979;3:155-74.

15. Felding I, Kristoffersson U, Sjöström H, Norén 0. Contribution to the18qsyndrome. A patient with del(18)(q22.3qter). Clin Genet 1987;31:206-10.

16. Keppler-Noreuil KM, Carroll AJ, Finley SC, Descartes M, Cody JD, DuPont $\mathrm{BR}$, et al. Chromosome 18q paracentric inversion in a family with mental retardation and hearing loss. Am J Med Genet 1998;76:372-8.

17. An GH, Kim MY, Kim MH, Kim YY, Choi KH, Kwak DW, et al. A prenatal case of paracentric inversion of chromosome 18, inv(18)(q21.1q22). J Genet Med 2012;9:101-3.

18. Neu RL, Brar HS, Koos BJ. Prenatal diagnosis of inv $(X)(q 12 q 28)$ in a male fetus. J Med Genet 1988;25:52-3.

19. Powell CM, Taggart RT, Drumheller TC, Wangsa D, Qian C, Nelson LM, et al. Molecular and cytogenetic studies of an $\mathrm{X}$; autosome translocation in a patient with premature ovarian failure and review of the literature. Am J Med Genet 1994;52:19-26.

20. Krauss CM, Turksoy RN, Atkins L, McLaughlin C, Brown LG, Page DC. Familial premature ovarian failure due to an interstitial deletion of the long arm of the X chromosome. N Engl J Med 1987;317:125-31.

21. Dar H, Tal J, Bar-el H, Halpern I, Sharf M. Paracentric inversion of Xq and ovarian dysfunction. Am J Med Genet 1988;29:167-70.

22. Warburton $D$, Twersky S. Risk of phenotypic abnormalities in paracentric inversion carriers. Am J Med Genet 1997;69:219.

23. Sutherland GR, Callen DF, Gardner RJ. Paracentric inversions do not normally generate monocentric recombinant chromosomes. Am J Med Genet 1995;59:390-2.

24. Madan K Menko FH. Intrachromosomal insertions: a case report and a review. Hum Genet 1992;89:1-9.

25. Madan K, Nieuwint AW. Reproductive risks for paracentric inversion heterozygotes: Inversion or insertion? That is the question. Am J Med Genet 2002;107:340-3. 